\title{
ESTUDO DO COMPORTAMENTO DE VARIÁVEIS DE SOLO UTILIZANDO O MODELO NOAH PARA UMA CULTURA DE ARROZ IRRIGADO
}

\author{
Andréa U. Timm ${ }^{1, *}$, Virnei S. Moreira ${ }^{2}$, Juliana G. Bittencourt ${ }^{3}$, Débora R. Roberti ${ }^{3}$, \\ Osvaldo L.L. de Moraes ${ }^{3}$, Gervásio A. Degrazia ${ }^{3}$ \\ ${ }^{1}$ Faculdade da Serra Gaúcha, FSG, Caxias do Sul, RS, Brasil \\ ${ }^{2}$ Universidade Federal do Pampa /UNIPAMPA, Itaqui, RS, Brasil \\ ${ }^{3}$ Universidade Federal de Santa Maria/ UFSM, Santa Maria, RS, Brasil \\ *andrea.timm@fsg.br
}

\section{RESUMO}

O presente trabalho tem por objetivo avaliar o desempenho do modelo de superfície Noah através da simulação de dados de solo e compará-los com dados observados em uma região com arroz irrigado no sul do Brasil. A partir dos resultados, observa-se que o modelo Noah necessita de ajustes, principalmente, quando analisado o parâmetro umidade volumétrica do solo.

\begin{abstract}
This study aims to evaluate the performance of the land surface model Noah by simulating soil data and compare them with observed data in a region with rice in southern Brazil. From the results, it is observed that the Noah model needs adjustments, especially when analyzing the parameter volumetric soil moisture.
\end{abstract}

\section{INTRODUÇÃO}

O estudo do comportamento de variáveis do solo é de fundamental importância para a descrição correta de modelos que descrevem a interação solo-superfície-atmosfera. Regiões com agricultura de irrigação geralmente não são representadas em modelos. Neste contexto, objetiva-se realizar um estudo do comportamento dessas variáveis de solo para uma cultura de arroz irrigado na região central do Rio Grande do Sul através de simulações utilizando o Modelo Noah.

\section{METODOLOGIA}

\section{MODELO DE SUPERFÍCIE NOAH}

O modelo de superfície usado neste trabalho é o Noah (Noah Land Surface Model) (Ek et al., 2003) do NCEP (National Centers for Environmental Prediction) versão off-line 2.7.1. O Noah evoluiu recebendo novas parametrizações físicas, entre elas aumento no número de camadas do solo, formulação da condutância do dossel (Chen et al., 1996), balanço de água e energia na superfície, evaporação do solo e fenomenologia de vegetação (Betts et al., 1996), reformulação das funções de infiltração e runoff (Schaake et al.,1996). Maiores detalhes do modelo veja Ek et al. (2003).

\section{DESCRIÇÃO DO SÍTIO EXPERIMENTAL}

O sítio experimental estava localizado na cidade de Paraíso do Sul (29\%44'39,6' S; $53^{\circ} 8$ ' $59,8^{\prime \prime} \mathrm{W} ; 108 \mathrm{~m}$ ), no sul do Brasil. O período de estudo foi entre 22 de julho de $2003 \mathrm{e}$ 21 de julho de 2004. O arroz foi plantado em 25NOV2003 e colhido em 04ABR2004. O 
restante do período a superfície permaneceu coberta somente com vegetação rasteira e durante praticamente o ciclo inteiro do cultivo do arroz (final de Dezembro à final de Março) a superfície permaneceu coberta com uma camada de água de $7-10 \mathrm{~cm}$.

Medidas de temperatura do solo foram realizadas em cinco níveis $(-2,-5,-10,-20$ e $-50 \mathrm{~cm})$ pelo STPO1 (Soil Temperature Profile) e de umidade do solo em seis níveis (-10, -20, -30, 40, -60 e $-100 \mathrm{~cm}$ ) pela Delta T Device Profile Prob PR1, todas coletadas na taxa de $1 \mathrm{~Hz}$.

\section{RESULTADOS}

A Figura 1 mostra a comparação entre as médias diárias observadas da temperatura do solo e simuladas pelo modelo Noah. É possível observar que o modelo representa satisfatoriamente esta variável durante todo o período, com pequenas diferenças no período do ciclo do arroz. No período da cultura, é visível a subestimação dos dados simulados pelo modelo para a temperatura do solo, que apresenta uma diferença máxima em torno de $5^{\circ} \mathrm{C}$. O problema do Noah em subestimar os dados de temperatura do solo, durante o período da cultura, pode estar relacionado ao fato de que o modelo simula a temperatura do solo considerando que a radiação incidente atinja diretamente sobre a superfície.

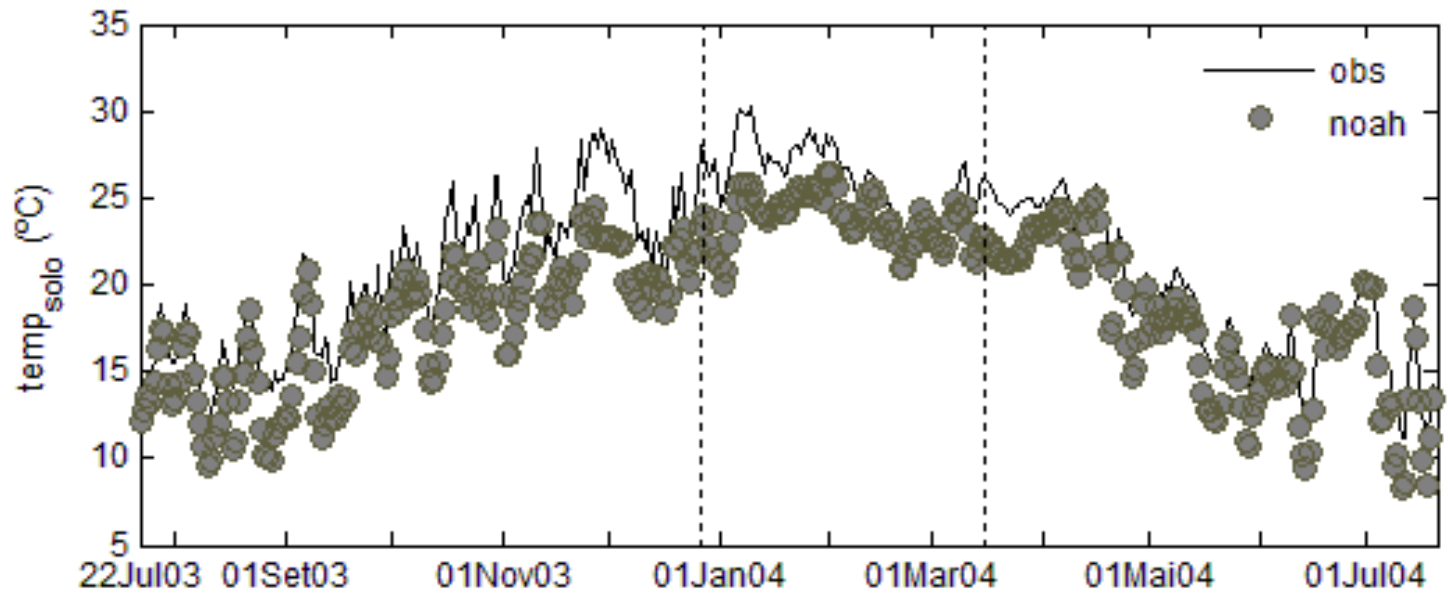

Figura 1 - Média diária da temperatura do solo observada a $5 \mathrm{~cm}$ e simulada na camada entre 0-10 cm de profundidade. Os pontilhados verticais indicam as datas de início e fim da irrigação, respectivamente.

Na Figura 2, é apresentada a comparação entre as médias diárias da umidade volumétrica observadas e simuladas para o período de novembro de 2003 a julho de 2004. As medidas realizadas a $10 \mathrm{~cm}$ de profundidade foram desconsideradas. Do modelo foram considerados somente os valores médios do centro da camada $(-5,-25,-75$ e $-150 \mathrm{~cm})$. Da Figura 2, observa-se que as três camadas mais profundas dos dados observados encontram-se completamente saturadas. No entanto, o modelo, mesmo nas camadas mais profundas, assume seus valores de acordo com a precipitação (resultado não apresentado). Verifica-se que o modelo apresentou dificuldade em simular a umidade volumétrica. Isso ocorre pois, durante praticamente todo o ciclo do arroz, a região encontra-se inundada pela lâmina de água. Ingwersen et al. (2010) utilizaram o modelo Noah, versão off-line 3.1, aplicado a uma cultura de trigo e também obtiveram dificuldades em simular a umidade volumétrica, concluindo que futuros estudos são necessários para melhorar a descrição desta propriedade. 


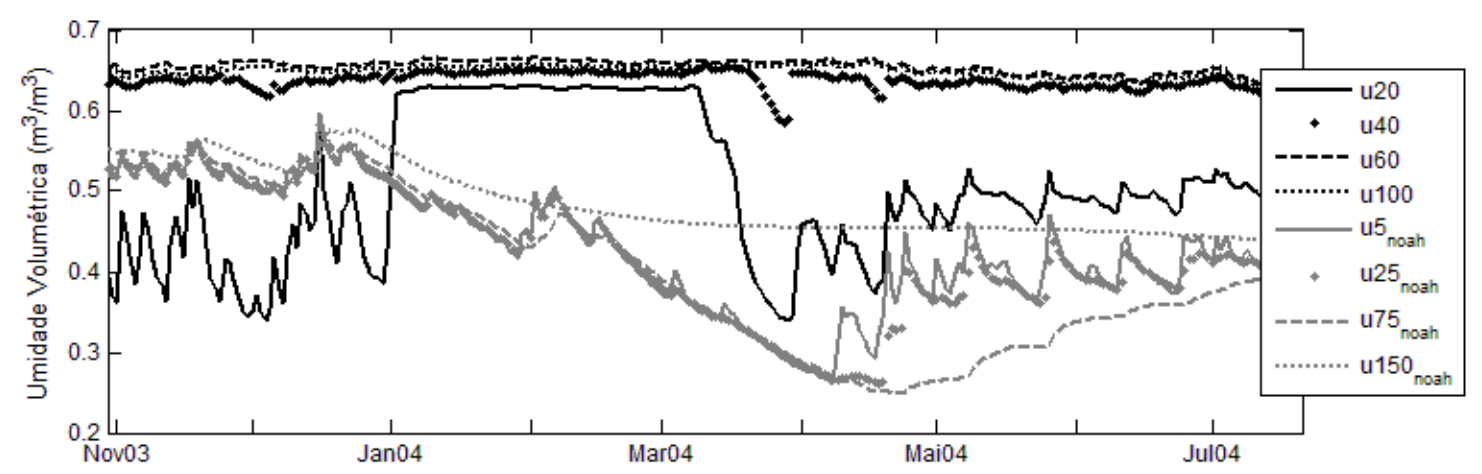

Figura 2 - Médias diárias dos valores simulados e observados da umidade volumétrica do solo para o sítio experimental de Paraíso do Sul - RS.

\section{CONCLUSÕES}

A partir da análise dos resultados, é possível concluir que o modelo Noah, para a variável temperatura do solo, apresentando flutuações diárias durante o período da cultura. Para a variável umidade volumétrica, o modelo necessita de ajustes durante todo o período. Isso pode estar relacionado à forma de cálculo deste parâmetro no modelo, pois a equação de Richards é falha para o cálculo de $\theta$ quando ocorrem transições abruptas de uma camada para outra.

\section{REFERÊNCIAS}

BETTS, A.K.; HONG, S.-Y.; PAN, H.-L. Comparison of NCEP-NCAR Reanalysis with 1987 fife data. Monthly Weather Review, v.124, n.7, 1996.

CHEN, F. et al. Modeling of land-surface evaporation by four schemes and comparisonwith five observations. Journal of Geophysical Research, v.101, n.D3, p.7251-7268, 1996.

EK, M.B. et al. Implementation of Noah land surface model advances in the National Centers for Environmental Prediction operational mesoscale Eta model. Journal of Geophysical Research, v.108, n.D22, 2003.

SCHAAKE, J. C. et al. Simple Water Balance Model for estimating runoff atdifferent spatial and temporal scales. Journal of Geophysical Research, v.101, n.D3, p.7461-7475, 1996. 